\title{
Economic Benefit Analysis of Solar Power Generation
}

\author{
Tianyi Qu ${ }^{1, a}$ and Xiaofang Cao ${ }^{1, b}$ \\ ${ }^{1}$ School of Management, XuZhou institute of Technology, Xuzhou, Jiangsu, China 221008 \\ ajdbh2001@163.com bcxfxzit@163.com
}

Keywords: Photovoltaic power generation; Environmental; Benefit; Cost; Income

\begin{abstract}
Due to the characteristics of environmental protection, photovoltaic power generation has been deeply loved by the energy sector of all countries, so they put great effort into research and development. The initial investment of photovoltaic power generation is large, and its construction and popularization should be based on the analysis of the economic benefits of science. It is helpful for the healthy development of PV system by evaluating and predicting the benefits of PV system in many ways.
\end{abstract}

\section{Introduction}

With the increasing shortage of traditional energy sources such as coal and the increasing environmental pollution, the application of clean new energy has been increasing. In the sequence of many new energy sources, solar power is showing an increasingly strong momentum of development. The initial investment of solar photovoltaic power generation is large, but at the same time, it can bring the benefits of power generation and low carbon efficiency. How to measure the relationship between the investment and economic benefits of photovoltaic power generation becomes an important factor to promote the photovoltaic system.

\section{The Characteristics of Photovoltaic Power Generation}

Photovoltaic power generation system is characterized by the production of solar cell components of the DC power, then the inverter converts DC to AC power which meets the standard of grid, finally, directly access to the public grid. The distribution of light resources and the randomness, imbalance, intermittency and volatility of solar radiation reduce the controllability of photovoltaic power plants. Therefore, the requirements of different capacity and grid connected photovoltaic power supply are different. In the term of the grid, because the characteristics of photovoltaic power generation is different from the conventional power generation, grid technology and access calculation method is no longer suitable for photovoltaic power plants on the other hand, there is no systematic research on the interaction between photovoltaic power grid and power grid, not meeting comprehensive, clear, workable management standards and technical specifications. Power companies have difficulty in credible evaluation of PV the power supply from power quality, reliability, stability, security and management comprehensively, so that the complexity and difficulty of PV are improved a lot.

Photovoltaic power grid is based on its capacity and the grid voltage level can choose 35,10 $\mathrm{kV}, 400 \mathrm{~V}$ and so on Photovoltaic power generation has the following characteristics:(1)The voltage source current control is the main control method of the existing photovoltaic grid connected inverter The current source is controlled by the input voltage source, and the output current is controlled to track the voltage and the grid voltage.(2)The maximum power point tracking control(MPPT) can effectively control the output power of grid connected inverter.(3)The output of photovoltaic power generation is affected greatly by the weather, and the power generation will change violently and quickly in cloudy weather.(4) Due to the rapid fluctuation of photovoltaic power station power when the large capacity grid is connected, the probability of the equivalent load peak-valley difference increases greatly, which is adjusted by the reserve capacity of the conventional generator set as a result, the generation cost of conventional generators will increase 
dramatically.(5)The harmonics will become larger because of the light output of the inverter. (6) The relevance between island protection and load condition of grid connected inverter.

\section{The Cost of Photovoltaic Power Generation}

Photovoltaic power system investment and operation and maintenance costs.

In the total life cycle, it refers to the total cost of equipment procurement, construction and operation maintenance for photovoltaic power generation system. Obviously, from the point of view of engineering economy, this part of the cost should consider the time value of funds.

$$
E_{1}=\sum_{t}\left(E_{t}+E_{o p t}\right)(1+i)^{-t}
$$

In the formula, $E_{1}$ is the investment and operation and maintenance costs of photovoltaic power generation system; $E_{t}$ is capital investment of the first $\mathrm{t}$ year; $E_{\text {opt }}$ is operation and maintenance costs of the first $t$ years (including fault repair and equipment replacement); $i$ is the discount rate.

Due to the increase in the reserve capacity of the system to pay the economic price

Because of the stability of photovoltaic power generation is not strong, in order to ensure the stable and reliable operation of the whole power system after the distributed photovoltaic access to the power system, they need to increase the reserve capacity. The cost of the capacity is calculated by using empirical value estimation, as shown in the following:

$$
E_{2}=D_{1} \cdot \int_{0}^{t} \alpha p_{\Delta}(t) d t
$$

In the formula, $D_{1}$ is the unit price of the spare quantity; $\alpha$ is the empirical coefficient; $p_{\Delta}(t)$ is the output capacity of $t$ time.

\section{Indirect environmental costs}

Although the photovoltaic system can bring less carbon emissions after operation, the photovoltaic power generation equipment in the manufacturing, transportation, installation can cause carbon emissions during operation and maintenance; in addition, the increase of standby capacity is related to the increase of carbon emissions. Based on the principle of fine calculation, the two parts should be included in the benefit evaluation model.

$$
E_{3}=\beta D_{T}\left(k P_{0} m_{c}+W g s+1\right)+D_{T} \int_{0}^{t} \alpha p_{\Delta}(t) d t
$$

In the formula, $\beta$ is the coefficient relationship between the equivalent carbon emissions in the operation and maintenance of the PV system and the equivalent carbon emission of the PV system investment; $D_{t}$ is the equivalent carbon emissions per unit price; $k$ is consumed by the photovoltaic power system production unit of electric energy; $m_{c}$ is the index of carbon dioxide emissions of thermal power plant; $p_{0}$ is a photovoltaic system installed capacity; $W$ is the total weight of photovoltaic modules; $g$ is the carbon emission intensity of equipment during transportation. The first half of the model is the equivalent carbon emission cost in the production and operation of the $\mathrm{PV}$ system, and the second part is the equivalent carbon emission cost.

\section{Revenue photovoltaic Power Generation System}

Electricity sales revenue

Assuming that in the entire $t$ year period, the price of the electricity sale unit remains unchanged, and the sales revenue for the year $t$ is: 


$$
E_{4}=D_{1} G_{t}
$$

In the formula, $G_{t}$ is the total amount of electricity sold in photovoltaic systems in year t.

Revenue of reducing network loss

Photovoltaic power generation system is usually installed in the area near the load, which is beneficial to reduce the transmission loss. The revenue generated in this section is as follows:

$$
E_{5}=D_{1} \int_{0}^{t}(W-W) d t
$$

In the formula, $W_{1}, W_{2}$ are the loss of the first year $\mathrm{t}$ of the grid before not installing the PV system and the loss after installation.

Indirect environmental income

The economic income of carbon emission reduction caused by photovoltaic power generation. This part of the income is indirect, which can be equivalent to carbon emission reduction and carbon trading price of the product. The carbon emission reduction refers to the same amount of electricity, the traditional thermal power plant emissions of carbon dioxide (including the loss of the network changes). This part of the income can be expressed as:

$$
E_{6}=D_{T} m_{c}\left[G_{t}+\left(W_{1}-W_{2}\right)\right]
$$

\section{Revenue of Photovoltaic Power Generation}

Through the above cost analysis and income analysis, income from the PV system is revenue minus cost. The income of the year $\mathrm{t}$ :

$$
E_{t}=E_{4}+E_{5}+E_{6}-E_{1}-E_{2}-
$$

Similarly, the benefits of the whole PV system life cycle:

$$
E=\sum_{t=1}^{m} E_{t}
$$

In the formula, $m$ is the life cycle of the whole PV system.

\section{Conclusion}

Photovoltaic power generation is a systematic project not only to alleviate the shortage of traditional primary energy, but also for the use of low-carbon environmental protection energy environment Therefore, the evaluation of the economic efficiency of photovoltaic power generation system, not only depends on how much power it sends, but also should consider the reduction of carbon emissions due to the use of photovoltaic The calculation of photovoltaic power generation energy-saving emission reduction and environmental benefits, which helps to compare with the traditional photovoltaic power generation mode and reduces photovoltaic power generation in the process of energy waste and pollution to the maximum extent makes photovoltaic power generation technology service for the environmental protection to a greater extent In the calculation of the environmental benefits of energy saving and emission reduction, there are still many factors which affect and restrict the accuracy of the calculation results So ,this requires further study.

\section{Reference}

[1] Walid EI-Khattam, Y G Hegazy, M M A Salama. An Integrated Distributed Generation Optimization Model for Distribution System Planning. In:IEEE Transactions on Power Systems;Vol20. 2005. 1158-116.

[2] Tripanagnostopoulos Y. Aspects and improvements of hybrid photovoltaic/thermal solar energy system[J]. Solar Energy, 2007, 81(9): 1117-1131. 
[3] Ringel M. Fostering the use of renewable energies in the European Union: the race between feed-in tariffs and green certificates[J]. Renewable energy, 2006, 31(1): 1-17.

[4] Beurskens L W M, Hekkenberg M, Vethman P. Renewable energy projections as published in the national renewable energy action plans of the European member states[J]. European Research Centre of the Netherlands (ECN) and European Environmental Agency (EEA), Petten, 2011.

[5] Klessmann C, Held A, Rathmann M, et al. Status and perspectives of renewable energy policy and deployment in the European Union-What is needed to reach the 2020 targets?[J]. Energy policy, 2011, 39(12): 7637-7657.

[6] Kitzing L, Mitchell C, Morthorst P E. Renewable energy policies in Europe: Converging or diverging[J]. Energy Policy, 2012, 51: 192-201.

[7] European Photovoltaic Industry Association. Global market outlook for photovoltaics until 2014[R]. Brussels, Belgium: European Photovoltaic Industry Association(EPIA ), 2010.

[8] Toshihiko Noguchi, Shigenori Togashi, and Ryo Nakamoto. Short-Current Pulse-Based aximum Power Point Tracking Method for Multiple Photovoltaic and Converter Module System[J]. IEEE Transactions on Industrial Electronics, 2002, 49(1): 21 223.

[9] Jaina, Choij, Kimb. Impact of integrating the photovoltaic and wind energy sources on generation system reliability and operation economics[C]/Proceedings of International Conference on Power System Technology, October 14 17, 2002, Kunming, China: 24372442.

[10] Owen Worley, Diego KIabjall. Optimization of battery charging and purchasing at electric vehicle battery swap-Stations[C],vehicle Power and Propulsion Conference (vppc), 2011 IEEE, 20M: $1-4$. 